\section{Detection of Acute Infections during HIV Testing in North Carolina}

\author{
Christopher D. Pilcher, M.D., Susan A. Fiscus, Ph.D., Trang Q. Nguyen, M.P.H., \\ Evelyn Foust, M.P.H., Leslie Wolf, Ph.D., Del Williams, Ph.D., Rhonda Ashby, B.S., \\ Judy Owen O'Dowd, B.S., J. Todd McPherson, M.S., Brandt Stalzer, B.S., \\ Lisa Hightow, M.D., William C. Miller, M.D., Ph.D., Joseph J. Eron, Jr., M.D., \\ Myron S. Cohen, M.D., and Peter A. Leone, M.D.
}

\section{ABSTRACT}

\section{BACK GROU N D}

North Carolina has added nucleic acid amplification testing for the human immunodeficiency virus (HIV) to standard HIV antibody tests to detect persons with acute HIV infection who are viremic but antibody-negative.

METHODS

To determine the effect of nucleic acid amplification testing on the yield and accuracy of HIV detection in public health practice, we conducted a 12-month observational study of methods for state-funded HIV testing. We compared the diagnostic performance of standard HIV antibody tests (i.e., enzyme immunoassay and Western blot analysis) with an algorithm whereby serum samples that yielded negative results on standard antibody tests were tested again with the use of nucleic acid amplification. A surveillance algorithm with repeated sensitive-less-sensitive enzyme immunoassay tests was also evaluated. HIV infection was defined as a confirmed positive result on a nucleic acid amplification test or as HIV antibody seroconversion.

RESULTS

Between November 1, 2002, and October 31, 2003, 109, 250 persons at risk for HIV infection who had consented to HIV testing presented at state-funded sites. There were 606 HIV-positive results. Established infection, as identified by standard enzyme immunoassay or Western blot analysis, appeared in 583 participants; of these, 107 were identified, with the use of sensitive-less-sensitive enzyme immunoassay tests, as recent infections. A total of 23 acutely infected persons were identified only with the use of the nucleic acid amplification algorithm. With all detectable infections taken into account, the sensitivity of standard antibody testing was 0.962 ( 95 percent confidence interval, 0.944 to 0.976 ). There were two false positive results on nucleic acid amplification tests. The specificity and positive predictive value of the algorithm that included nucleic acid amplification testing were greater than 0.999 ( 95 percent confidence interval, 0.999 to $>0.999$ ) and 0.997 ( 95 percent confidence interval, 0.988 to $>0.999$ ), respectively. Of the 23 acute HIV infections, 16 were detected at sexually transmitted disease clinics. Emergency measures for HIV prevention protected 48 sex partners and one fetus from highrisk exposure to HIV.

CONCLUSIONS

The addition of nucleic acid amplification testing to an HIV testing algorithm significantly increases the identification of cases of infection without impairing the performance of diagnostic testing. The detection of highly contagious, acutely infected persons creates new opportunities for HIV surveillance and prevention.
From the Departments of Medicine (C.D.P., B.S., L.H., W.C.M., J.J.E., M.S.C., P.A.L.), Microbiology and Immunology (S.A.F.), and Epidemiology (T.Q.N., W.C.M., M.S.C.), University of North Carolina at Chapel Hill, Chapel Hill; and the North Carolina Department of Health and Human Services HIV/ STD Prevention and Care Branch, Raleigh (E.F., L.W., D.W., R.A., J.O.O., J.T.M., P.A.L.). Address reprint requests to Dr. Pilcher at C.B. 7215, University of North Carolina at Chapel Hill, 211A W. Cameron Ave., Chapel Hill, NC 27599-7215, or at cpilcher@med. unc.edu.

N EnglJ Med 2005;352:1873-83.

Copyright $\odot 2005$ Massachusetts Medical Society. 
CUTE INFECTION WITH THE HUMAN immunodeficiency virus (HIV) is rarely recognized. It is associated with a high probability of secondary HIV transmission, ${ }^{1-5}$ probably because of the magnitude of viremia and genital shedding of virus. Since routine HIV antibody tests yield negative results during the first four to five weeks of HIV infection, ${ }^{6}$ acute infections can be diagnosed during this period only with the use of tests for viral antigens, nucleic acids, or both.

Sensitive nucleic acid amplification tests are routinely used by blood banks to protect the blood supply. ${ }^{7}$ However, concerns about cost and specificity have precluded the use of these tests for clinical testing for HIV, except in the evaluation of suspected acute retroviral syndromes. ${ }^{8}$ Results from several small studies, ${ }^{9-15}$ including one conducted in North Carolina, ${ }^{14}$ have suggested that acute (antibody-negative) infections that can be detected by nucleic acid amplification testing may be identified regularly in some clinical testing settings. Most recently, the use of algorithms ${ }^{12-15}$ involving the testing of pooled specimens has been proposed as a way to make nucleic acid amplification testing accurate and cost effective. ${ }^{14}$

We designed a system based on the concomitant use of nucleic acid amplification and antibody testing for the identification and public health management of patients with acute HIV infection who received voluntary counseling and testing in North Carolina. We report the results of the first year of this program.

METHODS

\section{STUDY DESIGN}

A 12-month observational study was conducted to evaluate a new strategy for HIV testing in North Carolina. The primary objective was to compare the performance and yield of standard HIV antibody tests with an algorithm that included both standard antibody tests and nucleic acid amplification tests. Additional objectives were to assess the feasibility of timely intervention in networks of social and sexual contact and to compare nucleic acid amplification tests with sensitive-less-sensitive enzyme immunoassay tests with respect to estimation of the incidence of HIV infection. ${ }^{16-18}$

\section{STUDY SUBJECTS}

All consenting persons who presented for HIV counseling and testing at 110 publicly funded sites in North Carolina participated in this study between November 1, 2002, and October 31, 2003. All testing was confidential and was linked to patient information with the use of a system of unique identifiers, according to state public health statutes. Anonymous, unlinked HIV testing is not available in North Carolina.

\section{STUDY PROCEDURES}

Figure 1 depicts the procedures of the North Carolina Department of Health and Human Services for HIV testing, field services (e.g., notification of test results and partner counseling), and surveillance, which provided the framework for this study. Information about characteristics of the testing sites, demographics, reasons for testing, HIV-testing history, and lifetime risk factors was taken from testing forms and entered into a secure database. Supplemental, detailed information about symptoms, risk behavior, and partnerships was collected at follow-up interviews from subjects with HIV tests positive for acute infection by specialists in HIV and sexually transmitted disease intervention. Written informed consent for all HIV testing and for the use of personal information in evaluation research was obtained during pretest counseling and at initial interviews with disease-intervention specialists. All testing and evaluation procedures were approved by institutional review boards of the state of North Carolina and the University of North Carolina School of Medicine.

\section{Standard HIV Antibody Testing}

Serum samples submitted for HIV testing were processed centrally at the North Carolina State Laboratory of Public Health and maintained at $-70^{\circ} \mathrm{C}$. Standard Vironostika HIV type 1 (HIV-1) enzyme immunoassay (bioMérieux) and Western blot analysis (Bio-Rad Laboratories) kits were used for antibody screening.

\section{Sensitive-Less-Sensitive Antibody Testing}

Antibodies that appear during the early stages of HIV infection are typically associated with a low titer. Janssen et al. ${ }^{16}$ developed a detuned antibody test (the "less sensitive" HIV antibody enzyme immunoassay) that continues to yield a negative result for 170 days, on average, after a standard ("sensitive") antibody enzyme immunoassay test becomes positive,${ }^{17}$ thereby allowing the identification of recent infections. For this study, serum samples that had positive results on the standard antibody en- 


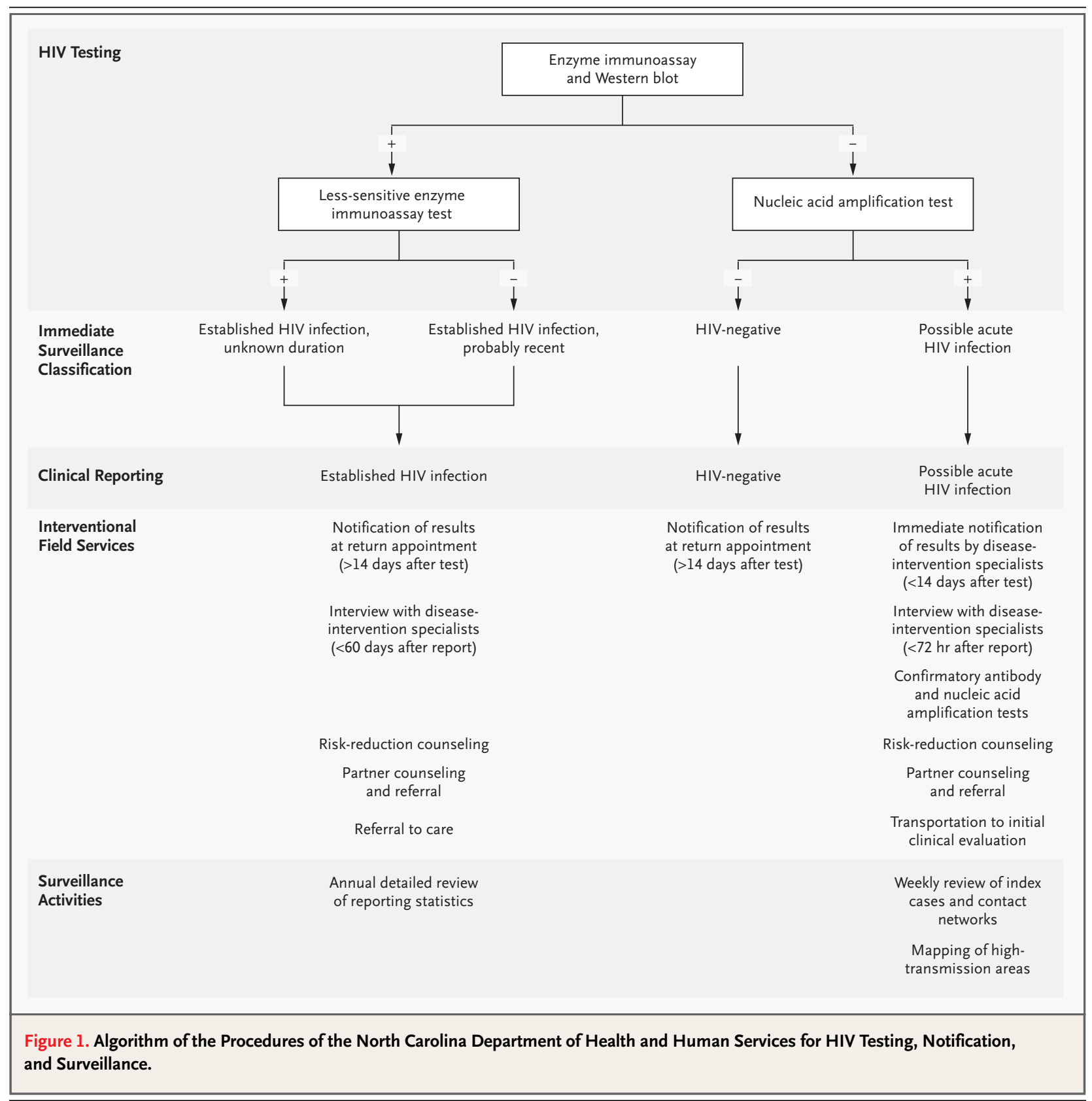

zyme immunoassay or Western blot analysis were made anonymous (unique identifiers were recoded) and then tested again at a laboratory certified by the Centers for Disease Control and Prevention (CDC) with the use of a less-sensitive HIV antibody enzyme immunoassay test based on the Vironostika kit. ${ }^{17}$

\section{Nucleic Acid Amplification Testing}

Serum samples that were antibody-negative or for which there was an indeterminate result were pooled, as previously described, ${ }^{14}$ with the use of an automated liquid-handling robot (Biomek FX, Beckman Coulter). The pooling algorithm allowed specimens to be screened by nucleic acid amplification in large groups, an approach that reduced testing costs and the potential for false positive results (which are expected to be approximately proportional to the number of tests performed). Pools of 10 samples were first created by combining aliquots from consecutive individual specimens; pools of 90 
were created by combining aliquots from 9 of these pools of 10 . The pools of 90 were then screened by nucleic acid amplification for HIV-1 RNA with the use of the NucliSens HIV-1 QL assay (bioMérieux), a qualitative assay that can reliably detect concentrations exceeding 75 copies of HIV-1 RNA per milliliter. A pool of 90 specimens, therefore, would be likely to be positive on nucleic acid amplification testing if the pool included at least 1 specimen with more than 6750 copies of HIV-1 RNA per milliliter. Nucleic acid amplification can occasionally detect even lower concentrations, depending on the efficiency of nucleic acid amplification in a testing run. ${ }^{19}$

Only pools of 90 specimens that were positive on nucleic acid amplification tests were broken down for further testing by this method - first by the examination of pools of 10 and finally by tests of individual specimens. Individual specimens that were positive on nucleic acid amplification underwent repeated enzyme immunoassay testing and quantitative HIV-1 RNA testing (Roche Amplicor 1.5, Roche Molecular Systems; lower detection limit, 500 copies per milliliter). Confirmatory serum samples obtained subsequently from subjects with possible acute HIV infection and their recent sexual contacts were tested individually for HIV antibodies and, if the results were negative, by nucleic acid amplification.

\section{Field Protocols}

North Carolina public health statutes mandate that the following functions be fulfilled by specialists in HIV and sexually transmitted disease intervention for all newly identified HIV-positive persons: namebased reporting, notification of HIV-positive persons of their test results, provision of risk-reduction counseling, and provision of partner counseling and referral services (Fig. 1). Cases of possible acute HIV infection, as determined by a positive result on a nucleic acid amplification test, and cases of documented seroconversion found during the routine evaluation of HIV reports were assigned to a team of 12 specifically trained disease-intervention specialists, who performed initial interviews, confirmatory tests, and referrals to care within 72 hours after receiving a report. For persons with possible acute HIV infection, initial counseling focused on the indeterminate nature of HIV test results and the urgent need for additional evaluation and confirmatory testing; repeated testing was recommended at 2 weeks (and, if necessary, at 4 and 12 weeks).
Sexual partners or those who had shared needles and hence had possibly been exposed to acute HIV infection within eight weeks before the initial interview were rapidly notified and offered testing. Partners who were exposed outside the eight-week window were notified only after confirmation of seroconversion in the index case.

\section{ANALYSES}

The population at risk for HIV infection was defined as the population of persons who did not report a previous positive HIV test. HIV infection was defined as a positive result on enzyme immunoassay and Western blot analysis at either the initial or follow-up test or as a positive result on nucleic acid amplification at both the initial and follow-up tests (Fig. 1). Persons for whom the HIV antibody status was negative or indeterminate but positive on initial nucleic acid amplification testing were defined as having acute HIV infection; those whose antibody status was positive on initial testing were defined as having established HIV infection. The performance of testing algorithms during screening of the routine testing population was evaluated on the basis of all detectable HIV infections according to the above-mentioned reference standard. The sensitivity of the combined algorithm and the specificity of the standard algorithm were assumed to be 100 percent. For surveillance purposes, after sensitive-less-sensitive enzyme immunoassay testing, subjects who had positive results on a sensitive enzyme immunoassay but negative results on a lesssensitive enzyme immunoassay were classified as probably having recent infection ${ }^{16,17}$; the remaining subjects, with positive results on a less-sensitive enzyme immunoassay, were classified as having infection of unknown duration, as recommended because of concerns about misclassification. ${ }^{20}$

\section{Estimation of Incidence}

Incidence rates were estimated from observational data on acute and recent HIV infections, according to the Serologic Testing Algorithm for Recent HIV Seroconversion. ${ }^{18}$ In this algorithm, the number of people in a population that are detected as having incident infection by an assay or assays $\left(\mathrm{N}_{\text {inc }}\right)$ can be divided by the window period in days (w) to give the number who have incident infection per day $\left(\mathrm{N}_{\text {inc }} / \mathrm{w}\right)$; $\mathrm{W}$ was assumed to be 170 days with the less-sensitive enzyme immunoassay ${ }^{17}$ and 28 days with nucleic acid amplification, ${ }^{6}$ yielding a window period of 198 days when both assays were used. 
The annual number was determined by multiplication of the observed number of incident infections per day by $365\left(365 \times \mathrm{N}_{\text {ind }} / \mathrm{w}\right)$. We divided this figure by the number at risk for infection in the population to obtain an estimate of the annual incidence rate $\left(\left[365 \times \mathrm{N}_{\text {ind }} / \mathrm{w}\right] /[\right.$ number at risk $\times 1$ year] $)$. HIVseronegative subjects and those with acute or recent HIV infections were included in this denominator. The 95 percent confidence interval for each estimate of incidence was calculated with the use of a Poisson distribution. ${ }^{18}$

\section{RESULTS}

\section{TESTING POPULATION}

Between November 2002 and October 2003, 110,890 persons sought publicly funded, voluntary HIV counseling and testing in North Carolina. The study population consisted of 109,250 subjects for whom there were complete testing data and who were classified as being at risk for HIV infection (Fig. 2). Forty-five percent of the subjects at risk were self-identified as black, 37 percent as white, and 15 percent as Hispanic. Most subjects underwent HIV testing at sexually transmitted disease clinics (41 percent); other testing sites included prenatal-obstetrical clinics (17 percent), familyplanning clinics (16 percent), freestanding HIV testing sites ( 11 percent), or jails ( 3 percent). Only 3 percent of subjects identified themselves as men who have sex with men, and 2 percent reported heterosexual contact and the use of injection drugs; 33 percent of the testing population self-identified as heterosexual, with no other risk factors.

\section{CASE IDENTIFICATION}

As detailed in Table 1, 606 new HIV infections were identified with the use of the enhanced algorithm (prevalence, 5.5 cases per 1000 persons at risk). Of those, 583 subjects had antibody-positive established infection (prevalence, 5.3 per 1000). On the basis of the results of sensitive-less-sensitive enzyme immunoassay tests suggesting low antibody titer, the surveillance algorithm defined 107 of the antibody-positive persons as probably having recent infection (prevalence, 1.0 per 1000). ${ }^{16,17} \mathrm{An}$ additional 23 persons were antibody-negative and had positive nucleic acid amplification test results and thus met the study definition of acute HIV infection (prevalence, 0.2 per 1000).

Overall, the use of nucleic acid amplification tests increased the rate of HIV case identification

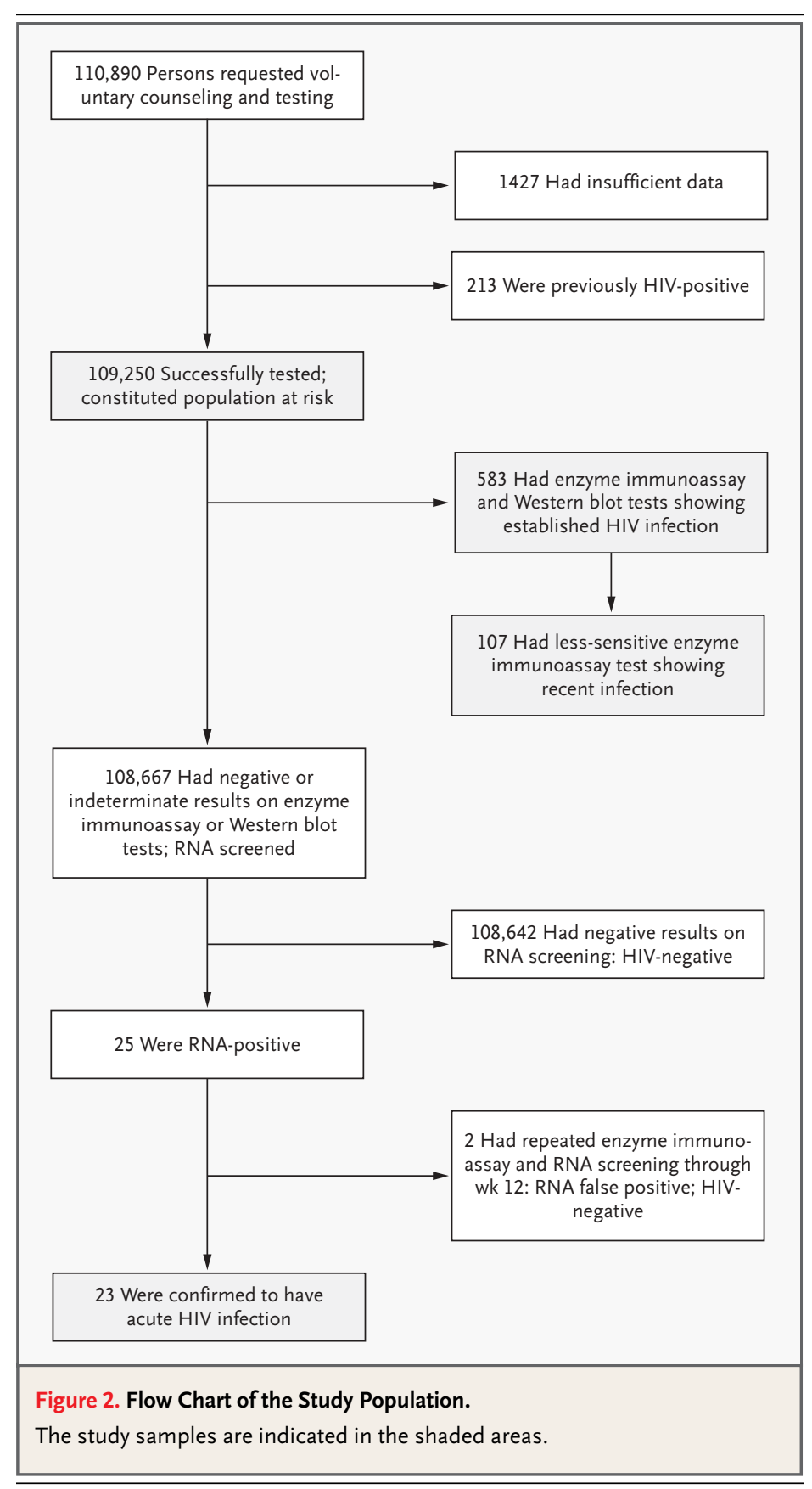

by 3.9 percent over that with standard antibody testing. Differences in the frequency of acute HIV infection were significant $(\mathrm{P}<0.001)$ across all types of confidential HIV testing sites, as illustrated in Figure 3. Most of the persons with acute infections (16 of 23 , or 70 percent) were identified at sexually transmitted disease clinics. The remainder of the acute infections were detected at freestanding HIV testing sites and atjails. 


\begin{tabular}{|c|c|c|c|c|c|c|c|c|}
\hline \multirow[t]{2}{*}{ Variable } & \multirow[t]{2}{*}{$\begin{array}{l}\text { No. } \\
\text { at Risk }\end{array}$} & \multicolumn{3}{|c|}{ No. of HIV-Positive Cases } & \multicolumn{4}{|c|}{ Prevalence of HIV-Positive Cases } \\
\hline & & Acute & Recent $\mathrm{Ab+}$ & All Ab+ & & Acute & $\begin{array}{c}\text { Recent Ab+ } \\
\text { no. } / 1000(95 \% \mathrm{Cl})\end{array}$ & All Ab+ \\
\hline All subjects & 109,250 & 23 & 107 & 583 & 0.2 & $(0.1-0.3)$ & $1.0(0.8-1.2)$ & $5.3(4.9-5.8)$ \\
\hline \multicolumn{9}{|l|}{ Sex广 } \\
\hline Male & 36,925 & 15 & 69 & 378 & 0.4 & $(0.2-0.7)$ & $1.9(1.4-2.3)$ & $10.2(9.2-11.3)$ \\
\hline Female & 70,900 & 8 & 38 & 200 & 0.1 & $(0.05-0.2)$ & $0.5(0.4-0.7)$ & $2.8(2.4-3.2)$ \\
\hline \multicolumn{9}{|l|}{ Aget: } \\
\hline$>24 \mathrm{yr}$ & 54,534 & 16 & 74 & 454 & 0.3 & $(0.2-0.5)$ & $1.4(1.1-1.7)$ & $8.3(7.6-9.1)$ \\
\hline$\leq 24 \mathrm{yr}$ & 53,318 & 7 & 31 & 122 & 0.1 & $(0.05-0.3)$ & $0.6(0.4-0.8)$ & $2.3(1.9-2.7)$ \\
\hline \multicolumn{9}{|l|}{ Race or ethnic background $\mathbb{S}$} \\
\hline White & 40,472 & 5 & 29 & 106 & 0.1 & $(0.04-0.3)$ & $0.7(0.5-1.0)$ & $2.6(2.1-3.1)$ \\
\hline Black & 48,796 & 16 & 64 & 410 & 0.3 & $(0.2-0.5)$ & $1.3(1.0-1.7)$ & $8.4(7.6-9.2)$ \\
\hline Hispanic & 16,627 & 1 & 14 & 53 & 0.1 & $(0.002-0.3)$ & $0.8(0.5-1.4)$ & $3.2(2.4-4.1)$ \\
\hline Native American & 1,137 & 1 & 0 & 4 & 0.9 & $(0.02-4.9)$ & $0 \quad(0-3.2)$ & $3.5(1.0-8.9)$ \\
\hline \multicolumn{9}{|l|}{ Risk categorył' } \\
\hline Heterosexual contact & 35,647 & 1 & 18 & 102 & 0.03 & $(0.001-0.2)$ & $0.5(0.3-0.8)$ & $2.9(2.3-3.5)$ \\
\hline $\begin{array}{l}\text { Presence of sexually transmitted } \\
\text { disease }\end{array}$ & 21,968 & 7 & 11 & 72 & 0.3 & $(0.1-0.7)$ & $0.5(0.3-0.9)$ & $3.3(2.6-4.1)$ \\
\hline Has a sex partner at risk & 19,975 & 2 & 23 & 141 & 0.1 & $(0.01-0.4)$ & $1.2(0.7-1.7)$ & $7.1(5.9-8.3)$ \\
\hline $\begin{array}{l}\text { Does not have an acknowledged } \\
\text { sex partner }\end{array}$ & 12,715 & 0 & 5 & 20 & 0 & $(0-0.3)$ & $0.4(0.1-0.9)$ & $1.6(1.0-2.4)$ \\
\hline $\begin{array}{l}\text { Has a sex partner and uses non- } \\
\text { injection drugs }\end{array}$ & 6,077 & 2 & 2 & 17 & 0.3 & $(0.04-1.2)$ & $0.3(0.04-1.2)$ & $2.8(1.6-4.5)$ \\
\hline Man who has sex with men & 3,777 & 7 & 37 & 170 & 1.9 & $(0.7-3.8)$ & $9.8(6.9-13.5)$ & $45.0(38.6-52.1)$ \\
\hline Heterosexual and uses injection drugs & 2,471 & 1 & 5 & 26 & 0.4 & $(0.01-2.3)$ & $2.0(0.7-4.7)$ & $10.5(6.9-15.4)$ \\
\hline Victim of sexual assault & 1,416 & 1 & 1 & 2 & 0.7 & $(0.02-3.9)$ & $0.7(0.02-3.9)$ & $1.4(0.2-5.1)$ \\
\hline $\begin{array}{l}\text { Categories that were included contained at } \\
\text { HIV infection as determined by a positive re } \\
\text { fection as determined by a positive result on } \\
\text { all } A b+\text { an HIV antibody-positive result on a } \\
\text { Differences in the prevalence of acute infect } \\
\text { Differences in the prevalence of acute or rec } \\
\text { Race and ethnic background were self-repor }\end{array}$ & $\begin{array}{l}\text { least } 100 \\
\text { esult on a } \\
n \text { a sensiti } \\
\text { an enzym } \\
\text { tion and i } \\
\text { cent infec }\end{array}$ & $\begin{array}{l}\text { subjects } \\
\text { ucleic ac } \\
\text { e enzym } \\
\text { immunc } \\
\text { the pre } \\
\text { on were }\end{array}$ & $\begin{array}{l}\text { 5; data were } n \\
\text { cid amplificat } \\
\text { e immunoass } \\
\text { oassay and W } \\
\text { valence of acL } \\
\text { significant (P }\end{array}$ & $\begin{array}{l}\text { not availa } \\
\text { tion test, } \\
\text { say and a } \\
\text { Nestern b } \\
\text { cute or re } \\
(P<0.05) \text {. }\end{array}$ & $\begin{array}{l}\text { le for } \\
\text { ecent } \\
\text { egati } \\
t \text { ana } \\
\text { nt in }\end{array}$ & $\begin{array}{l}\mathrm{r} \text { all subjects } \mathrm{i} \\
\mathrm{t} \mathrm{Ab}+\text { the likel } \\
\text { tive result on } \\
\text { alysis, and } \mathrm{Cl} \\
\text { fection were }\end{array}$ & $\begin{array}{l}n \text { every category. Ac } \\
\text { ihood that a patient } \\
\text { less-sensitive enzy } \\
\text { confidence interval. } \\
\text { significant }(P<0.05)\end{array}$ & $\begin{array}{l}\text { ute denotes acute } \\
\text { has recent HIV in- } \\
\text { ne immunoassay, } \\
P<0.05) \text {. }\end{array}$ \\
\hline
\end{tabular}

As shown in Table 1, acute and recent HIV infections were generally more prevalent among men, black persons, and persons older than 24 years than among other demographic groups. There was also a significantly increased prevalence of both acute and recent HIV infections among men who have sex with men and among persons tested for HIV infection as a result of having another sexually transmitted disease.

\section{Signs and Symptoms of Acute Infection}

No subjects were believed, on clinical grounds, to have acute HIV infection at the time of testing, although it was determined retrospectively that 7 of the 23 subjects who met the study definition of acute infection (30 percent) had presented with symptoms of acute retroviral illness. ${ }^{21}$ Symptoms developed in an additional six subjects (26 percent) during the seroconversion period. Eight subjects 


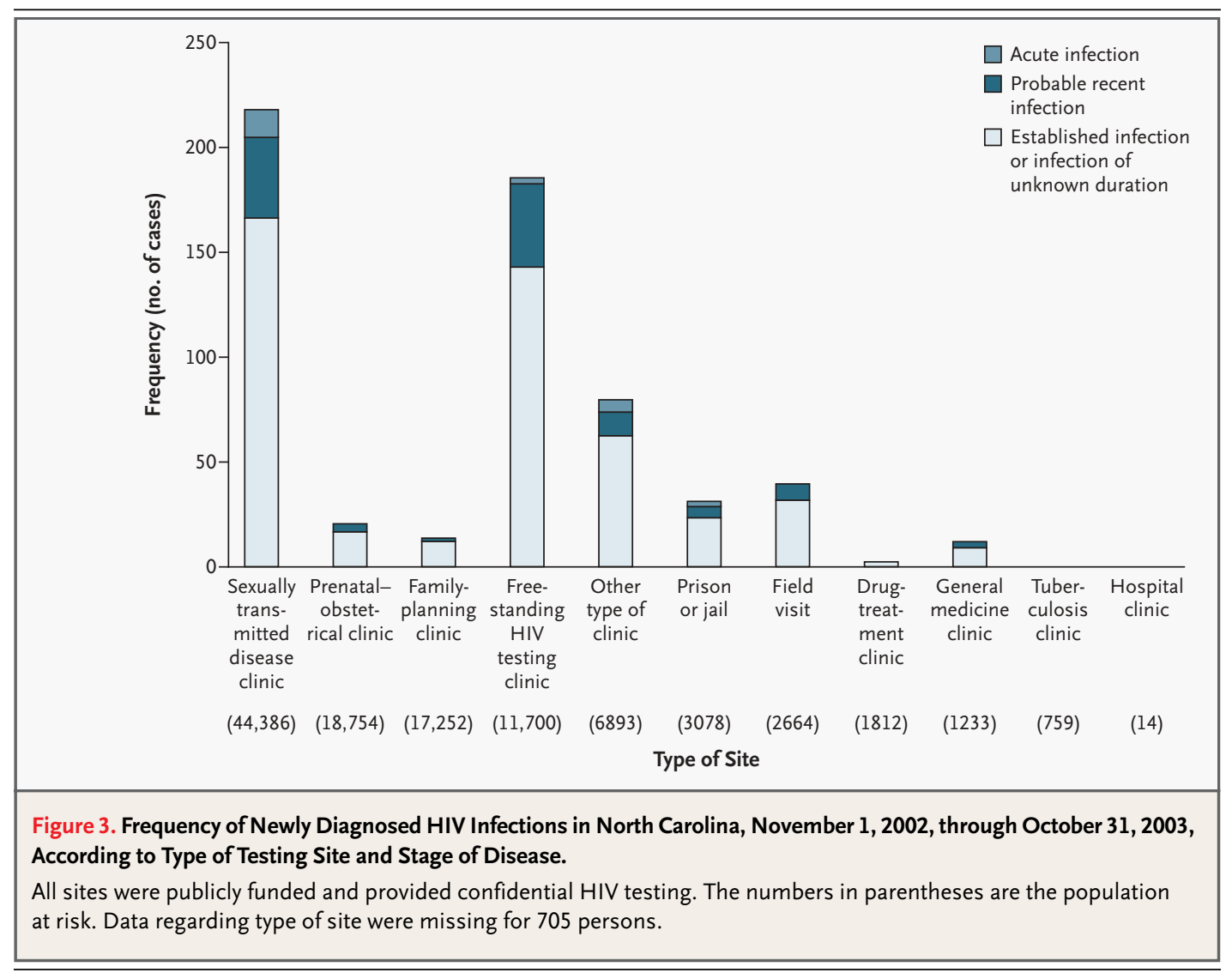

reported symptoms related to a sexually transmitted disease, and one was pregnant. The median HIV-1 viral load on initial testing was 258,000 copies of HIV-1 RNA per milliliter, with a range of 2609 to $4,998,000$ copies per milliliter.

\section{PERFORMANCE OF DIAGNOSTIC TESTS}

Follow-up testing demonstrated antibody seroconversion in 20 of 25 persons who had tested positive on nucleic acid amplification. Two persons were again positive on nucleic acid amplification and antibody negative on initial follow-up testing, but they refused further testing. In one person who was followed up for 12 months, Pneumocystis carinii pneumonia and the acquired immunodeficiency syndrome developed, but HIV antibodies were not detected. Two patients had negative results on both nucleic acid amplification and antibody testing at follow-up and were classified as having false positive results.

The estimate of sensitivity for the standard antibody-testing algorithm was 0.962 ( 95 percent confidence interval, 0.944 to 0.976 ). The positive predictive value of the algorithm that combined standard antibody testing and nucleic acid amplification testing with pooling was 0.997 (95 percent confidence interval, 0.988 to $>0.999$ ). The positive predictive value of nucleic acid amplification with pooling alone was 0.920 (95 percent confidence interval, 0.740 to 0.990 ). The specificity of nucleic acid amplification testing with pooling was greater than 0.999 (95 percent confidence interval, 0.999 to $>0.999$ ).

\section{INTERVENTIONS TARGETING ACUTE INFECTION}

All subjects with acute infection were notified of their infection, 17 of the 23 (74 percent) within 72 hours after the test result became available. No adverse events (e.g., psychological trauma, violence against or from partners, violation of confidentiality, or inappropriate HIV therapy) were reported during follow-up. Twenty-one subjects with acute infection successfully began specialty medical care, and 20 of them, including 1 pregnant woman, received antiretroviral drug therapy from their personal physicians. The offspring of the pregnant woman was HIV-negative.

Forty-eight sexual partners of subjects with acute 
HIV infection received counseling for risk reduction. Eighteen of these partners (38 percent) had HIV infection - in 13 cases ( 27 percent) previously recognized and in 5 (10 percent) newly detected. Eleven of the partners were probably the source of the acute HIV infections. Ten of these possible transmitters were aware of their HIV infection, but only three had disclosed their status to their partners. Three of the possible transmitters had been named in surveillance records as a potential source of infection in at least three other cases, suggesting a possible role as "core transmitters." 22

\section{SOCIAL NETWORKS AND RISK ASSOCIATIONS}

Disease-intervention specialists collected data on the social networks of acutely infected subjects through in-depth interviews. Eleven of 15 acutely infected men named male sexual partners at the time of the interview, whereas only 7 had reported on their testing form that they had sex with men. Social factors that were identified as possibly contributing to the risk of transmission in the 23 index cases of acute infection included recent prison release ( 5 subjects), sex work (5), multiple anonymous sexual partnerships (4), and heavy drug or alcohol use (10).

Four subjects with acute HIV infection were college students; two in one town were identified within one month of each other. Surveillance records were examined with the use of traditional outbreakinvestigation techniques for evidence of increased rates of HIV infection among college students and noncollege students; this review revealed a new HIV outbreak in both student groups that had begun across North Carolina in mid-2001 among young black men who have sex with men. ${ }^{23}$

\section{ESTIMATION OF INCIDENCE ON THE BASIS} OF ACUTE AND RECENT INFECTIONS

When used in conjunction with an algorithm based on sensitive-less-sensitive enzyme immunoassays, nucleic acid amplification testing increased the number of incident cases available for the estimation of incidence of HIV infection by 21 percent. Incidence rates that were calculated only on the basis of acute HIV infections (as detected on nucleic acid amplification tests) correlated strongly with incidence rates that were calculated only on the basis of recent HIV infections (as detected by sensitiveless-sensitive enzyme immunoassays) across both demographic categories $\left(\mathrm{r}^{2}=0.95\right)$ and risk categories $\left(r^{2}=0.95\right)$ with sufficient sample size. The inclusion of data from nucleic acid amplification testing did not change the estimated incidence rate by more than 5 percent in either direction for large patient categories that included men, women, men who have sex with men, black persons, and white persons.

With the use of the combined data from nucleic acid amplification testing and sensitive-lesssensitive enzyme immunoassays, the overall incidence in the study population was estimated at 2.2 HIV infections per 1000 person-years ( 95 percent confidence interval, 1.8 to 2.6). The measured incidence was higher among blacks (3.0 infections per 1000 person-years; 95 percent confidence interval, 2.4 to 3.8) than among whites (1.6 infections per 1000 person-years; 95 percent confidence interval, 1.0 to 2.1) and higher among persons older than 24 years (3.0 infections per 1000 personyears; 95 percent confidence interval, 2.4 to 3.7) than among those 24 years of age or younger (1.3 infections per 1000 person-years; 95 percent confidence interval, 0.9 to 1.8 ). A higher estimated incidence of HIV among men (4.3 infections per 1000 person-years; 95 percent confidence interval, 3.3 to 5.2) than among women (1.2 infections per 1000 person-years; 95 percent confidence interval, 0.8 to 1.6) was driven by the much higher incidence rate among the small number of men who reported having sex with men (21.4 infections per 1000 person-years; 95 percent confidence interval, 15.6 to 28.8).

\section{$\cos t s$}

Costs associated with nucleic acid amplification testing required a $\$ 402,861$ (3.3 percent) increase over the annual budget of $\$ 12,053,465$ dedicated to other HIV-related services - education, counseling, testing, field services, and surveillance activities (summarized in Fig. 1) - for the same year. Sixty-three percent of the additional costs $(\$ 251,900)$ went to specimen pooling and supplies used in nucleic acid amplification testing, including capital equipment costs; the remaining funds supported the shipment of specimens, technologists' time, administration, reporting of results, and management of data. The total expenditure for nucleic acid amplification testing reflected an added cost of $\$ 3.63$ per processed specimen and $\$ 17,515$ per additional diagnosed index case of HIV infection. This costeffectiveness reflected the use of one nucleic acid amplification test per approximately 80 specimens submitted. 


\section{DISCUSSION}

In this study, we found that antibody tests alone detected only 96 percent of HIV infections, as compared with an algorithm that included nucleic acid amplification tests to detect acute HIV infections. There are three principal reasons why the detection of such infections is especially important. First, the recognition of acute HIV infection allows appropriate clinical management. For the infected person, a prompt diagnosis can prevent the administration of inappropriate tests and therapies often used to evaluate and treat the symptoms of acute retroviral infection. ${ }^{24}$ When indicated, antiretroviral therapy can be provided. The hypothesis that even shortterm antiretroviral therapy that is initiated in patients with acute HIV infection may delay the progression of disease $\mathrm{e}^{25}$ is currently being evaluated in clinical trials.

Second, the identification of persons with acute HIV infection can help prevent further transmission of the virus. The probability of transmission is high during the first few months after acute HIV infection, ${ }^{1-5,26}$ during which time patients have a high viral burden in the blood and genital tract ${ }^{1}$ and are likely to engage in risky sexual behavior. ${ }^{27}$ Standard voluntary counseling and testing practices for HIV identify many patients as HIV-positive with advanced disease, ${ }^{28,29}$ after most sexual transmission is likely to have occurred already. ${ }^{3}$ The present study demonstrated that notification of results, access to antiretroviral therapy, and partner counseling and referral services can be instituted for acutely infected persons within days after testing.

Third, the identification of acute infections can improve HIV surveillance. Standard antibody tests limit surveillance to the monitoring of populations living with latent or advanced HIV disease. Since 1998 , the CDC has attempted to develop tests to distinguish recent from established antibody-positive HIV infections. To date, antibody-based assays that are used to determine incidence have not proved accurate enough to guide clinical management or epidemiologic investigation, ${ }^{20}$ and these tests miss all acute infections. The most widely used of these antibody assays is now the CDC's sensitive-less-sensitive enzyme immunoassay, which demonstrates reduced antibody titers among patients within 170 days after seroconversion. ${ }^{16,17}$ This test allows efficient estimation of HIV-infection incidence rates from cross-sectional sampling of populations, as described above. ${ }^{16-18}$ For pas- sive surveillance based on clinical testing, estimates of incidence are most appropriately used to monitor trends in incidence prospectively within testing populations defined by demographic factors or risk factors. ${ }^{18,20,30}$ In this study, we demonstrated that nucleic acid amplification testing and the sensitiveless-sensitive assay were complementary. In our patient population, the addition of nucleic acid amplification testing increased the number of detected incident cases by 21 percent over sensitive-lesssensitive enzyme immunoassay testing alone, thereby increasing the precision of estimates of incident cases for ongoing monitoring, without adding misclassification error. These findings demonstrate the potential of nucleic acid amplification testing to increase the accuracy and precision of data for both passive and active surveillance of HIV incidence.

The identification of acute cases also created the opportunity for public health officials to investigate HIV-transmission events systematically. Data from these investigations provided new details about the populations that were acquiring and transmitting HIV in North Carolina. The early detection of an ongoing outbreak of HIV infection across the state among young black men who have sex with men $^{23}$ exemplified the sensitivity of this approach in the identification of epidemiologic trends and hidden populations at risk for HIV infection.

This study had several additional, unexpected findings. More than two thirds of the acute cases were detected among the one third of the study participants who were tested at sexually transmitted disease clinics. This indicates that the use of nucleic acid amplification testing in sexually transmitted disease clinics can readily identify persons with both acute HIV infection and acute cases of other sexually transmitted diseases, possibly representing cotransmission of HIV and classic sexually transmitted pathogens. This dually infected population may be very likely to transmit HIV as a result of extreme HIV shedding in genital secretions. ${ }^{1,31}$ We also noted that only 30 percent of patients had symptoms of acute retroviral infection at the time they tested positive on nucleic acid amplification, indicating that limitation of this type of testing to patients with symptoms would be counterproductive.

Finally, we noted that an automated, highthroughput approach to specimen pooling resulted in excellent performance and cost-effectiveness with nucleic acid amplification tests. The total added testing cost of $\$ 3.63$ per specimen (inclusive of all costs for equipment, kits, labor, and adminis- 
tration) increased the overall costs of HIV testing and surveillance in North Carolina by only about 3 percent. Costs were lower than would be expected for any alternative methods used to diagnose acute HIV infection, including individual nucleic acid amplification tests, p24-antigen tests, or fourth-generation antigen-antibody enzyme immunoassay tests. Formal cost-effectiveness studies of nucleic acid amplification testing should be conducted. We noted substantial variation in the recognition of acute HIV infection among the types of testing sites and the categories of risk and demographic characteristics in this study; additional studies are needed to explore whether such criteria might help guide the use of supplemental nucleic acid amplification testing.

The inclusion of all state-funded testing performed during an entire year ensured that the present study would accurately reflect testing performance in public health practice. The generalizability of our findings to other states or to private medical-practice settings is less clear, although other preliminary data strongly suggest that many other testing populations (e.g., persons presenting at urgent care and emergency departments or at highrisk clinics) ${ }^{9-13}$ are expected to harbor a greater number and proportion of acute HIV infections that are missed by current antibody testing than North Carolina's general testing population. We believe that the work that has been done to date with nucleic acid amplification testing for HIV is now sufficient to allow us to conclude that this form of testing should be a standard tool for the prevention and surveillance of HIV infection and for the care of infected persons.

Supported in part by grants from the National Institutes of Health (NIMH-R01 068686, NIAID-K23 001781, and NIDDK-R01 049381), from the University of North Carolina Center for AIDS Research
(NICHD/NIAID 9-P30-AI50410), and from the General Clinical Research Center (RR-00046); and by an Association of Schools of Public Health-Centers for Disease Control and Prevention-Agency for Toxic Substances and Disease Registry Cooperative Agreement.

Dr. Pilcher reports having received grant support from Gen-Probe, Gilead, and Bristol-Myers Squibb; Dr. Fiscus, consultation or lecture fees from Scynexis and Becton Dickinson; Mr. McPherson, consultation or lecture fees from bioMérieux; Dr. Hightow, consultation or lecture fees from Gilead; Dr. Eron, consultation or lecture fees from Roche, Virco, GlaxoSmithKline, Abbott Laboratories, Bristol-Myers Squibb, and ViroLogic and grant support from Panacos Pharmaceuticals, Abbott Laboratories, and GlaxoSmithKline; and Dr. Leone, consultation or lecture fees from Gen-Probe and GlaxoSmithKline and grant support from GlaxoSmithKline.

We are indebted to the staff of the North Carolina State Laboratory of Public Health Serology/Virology Laboratory (Ini Ikpe for pooling and Regina Lee and Juanita Harris for assistance with protocol development, data collection, and management) for all antibody testing and nucleic acid amplification testing for the North Carolina Department of Health and Human Services Screening and Tracing Active Transmission program; to Ada Cachafeiro of the University of North Carolina Center for AIDS Research Retrovirology Core Laboratory for performing the less-sensitive enzyme immunoassay testing; to Mark Turner, Amy James, Paul Alabanza, and Priya Joshi for assistance with the handling of specimens and data and with training in nucleic acid amplification testing for the staff of the state laboratory; to Melissa Kerkau for performing quantitative viral load testing at the University of North Carolina; and, especially, to Bill Petz and Todd Vanhoy, the Disease Intervention Specialists of the HIV/STD Prevention and Care Branch of the North Carolina Department of Health and Human Services, for protocol development, training, and supervision of the STAT DIS team, which included Ramsay Hoke, Steve Beagle, Patrick McBride, Kristen Hancock, Kari Whisnant, Bernard Davis, Antonio Jones, Melissa Peoples, Leigh Cutler, Lateacha Hodge, and Vonetta Bethea - all showed extraordinary dedication and were responsible for all interviews and primary data collection; to Dr. Pia MacDonald for valuable technical assistance and John Peebles for assistance with the assembly of budget information; to Dr. Steve Cline for leadership within the health department; to Drs. Robert Ryder and Ron Swanstrom for leadership and funding for project development; to Drs. Frederick Sparling, Bernard Branson, and Sonia Napravnik for critical review of the manuscript; to bioMérieux and Mike Cronin, in particular, for in-kind support during the pilot phase of program implementation that included the nucleic acid testing kits for Screening and Tracing Active Transmission testing; and to Judith Finlay and Beckman Coulter for providing the Biomek FX robot and technical assistance during the initial pilot phase of the program.
REFERENCES

1. Pilcher CD, Tien HC, Eron JJ Jr, et al. Brief but efficient: acute HIV infection and the sexual transmission of HIV. J Infect Dis 2004;189:1785-92.

2. Leynaert B, Downs AM, de Vincenzi I. Heterosexual transmission of human immunodeficiency virus: variability of infectivity throughout the course of infection. Am J Epidemiol 1998;148:88-96.

3. Wawer MJ, Gray RH, Sewankambo D, et al. HIV-1 transmission per coital act by stage of HIV-1 infection, Rakai, Uganda. J Infect Dis (in press).

4. Peterman TA, Stoneburner RL, Allen JR, Jaffe HW, Curran JW. Risk of human immunodeficiency virus transmission from hetero- sexual adults with transfusion-associated infections. JAMA 1988;259:55-8. [Erratum, JAMA 1989;262:502.]

5. Jacquez JA, Koopman JS, Simon CP Longini IM Jr. Role of the primary infection in epidemics of HIV infection in gay cohorts. J Acquir Immune Defic Syndr 1994;7:1169 84.

6. Fiebig EW, Wright DJ, Rawal BD, et al. Dynamics of HIV viremia and antibody seroconversion in plasma donors: implications for diagnosis and staging of primary HIV infection. AIDS 2003;17:1871-9.

7. Schreiber GB, Busch MP, Kleinman SH, Korelitz JJ. The risk of transfusion-transmitted viral infections: the Retrovirus Epidemi- ology Donor Study. N Engl J Med 1996;334: 1685-90.

8. Daar ES, Little S, Pitt J, et al. Diagnosis of primary HIV-1 infection. Ann Intern Med 2001;134:25-9.

9. Rosenberg ES, Caliendo AM, Walker BD. Acute HIV infection among patients tested for mononucleosis. N Engl J Med 1999;340:969.

10. Pincus JM, Crosby SS, Losina E, King ER, LaBelle C, Freedberg KA. Acute human immunodeficiency virus infection in patients presenting to an urban urgent care center. Clin Infect Dis 2003;37:1699-704.

11. Clark SJ, Kelen GD, Henrard DR, et al. Unsuspected primary human immunodefi- 
ciency virus type 1 infection in seronegative emergency department patients. J Infect Dis 1994;170:194-7.

12. Morandi PA, Schockmel GA, Yerly S, et al. Detection of human immunodeficiency virus type 1 (HIV-1) RNA in pools of ser negative for antibodies to HIV-1 and HIV-2. J Clin Microbiol 1998;36:1534-8.

13. Quinn TC, Brookmeyer R, Kline R, et al Feasibility of pooling sera for HIV-1 vira RNA to diagnose acute primary HIV-1 infection and estimate HIV incidence. AIDS 2000; 14:2751-7.

14. Pilcher CD, McPherson JT, Leone PA, et al. Real-time, universal screening for acute HIV infection in a routine HIV counseling and testing population. JAMA 2002;288:21621.

15. Pilcher CD, Price MA, Hoffman IF, et al. Frequent detection of acute primary HIV infection in men in Malawi. AIDS 2004;18 517-24.

16. Janssen RS, Satten GA, Stramer SL, etal. New testing strategy to detect early HIV-1 infection for use in incidence estimates and for clinical and prevention purposes. JAMA 1998;280:42-8. [Erratum, JAMA 1999;281: 1893.]

17. Kothe D, Byers RH, Caudill SP, et al. Performance characteristics of a new less sensitive HIV-1 enzyme immunoassay for use in estimating HIV seroincidence. J Acquir Immune Defic Syndr 2003;33:625-34.
18. McDougal JS, Pilcher CD, Parekh B, et al. Surveillance for HIV-1 incidence using tests for recent infection. AIDS Suppl (in press).

19. Brambilla DJ, Jennings C, Morack R, Granger S, Bremer JW. Comparison of the sensitivities of the version 1.5 and version 1.0 ultrasensitive Roche Amplicor HIV-1 Monitor kits at low concentrations of human immunodeficiency virus RNA. J Clin Microbiol 2004;42:2819-20.

20. Reed C, Branson B, Janssen R. Interpreting STARHS results for individuals vs. estimation of HIV incidence. Presented at the 11th Conference on Retroviruses and Opportunistic Infections, San Francisco, February 8-11, 2004. abstract.

21. Bollinger RC, Brookmeyer RS, Mehendale SM, et al. Risk factors and clinical presentation of acute primary HIV infection in India. JAMA 1997;278:2085-9.

22. Thomas JC, Tucker MJ. The developmen and use of the concept of a sexually transmitted disease core. J Infect Dis 1996;174 Suppl 2:S134-S143.

23. Hightow LB, MacDonald P, Pilcher $\mathrm{CD}$, et al. The unexpected movement of the HIV epidemic in the Southeastern United States: transmission among college students, J Acquir Immune Defic Syndr. 2005; 38:531-7.

24. Weintrob AC, Giner J, Menezes P, et al. Infrequent diagnosis of primary human immunodeficiency virus infection: missed opportunities in acute care settings. Arch Intern Med 2003;163:2097-100.

25. Rosenberg ES, Altfeld M, Poon SH, et al. Immune control of HIV-1 after early treatment of acute infection. Nature 2000;407: 523-6.

26. Pilcher CD, Eron JJ Jr, Vernazza PL, et al. Sexual transmission during the incubation period of primary HIV-1 infection. JAMA 2001;286:1713-4.

27. Colfax GN, Buchbinder SP, Cornelisse PG, VittinghoffE, Mayer K, Celum C. Sexual risk behaviors and implications for secondary HIV transmission during and after HIV seroconversion. AIDS 2002;16:1529-35.

28. Valdiserri RO, Holtgrave DO, West GR Promoting early HIV diagnosis and entry into care. AIDS 1999;13:2317-30.

29. Dybul M, Bolan R, Condoluci D, et al. Evaluation of initial CD4+ T cell counts in individuals with newly diagnosed human immunodeficiency virus infection, by sex and race, in urban settings. J Infect Dis 2002; 185:1818-21.

30. Schoenbach VJ, Poole C, Miller WC. Invited commentary: should we estimate incidence for undefined populations? Am J Epidemiol 2001;153:935-7.

31. Galvin SR, Cohen MS. The role of sexually transmitted diseases in HIV transmission. Nat Rev Microbiol 2004;2:33-42.

Copyright $\odot 2005$ Massachusetts Medical Society.

\section{PHYSICIAN-JOURNALIST}

The Journal is seeking a physician with substantial reporting experience to write occasional articles on timely topics in medicine and society for the Perspective section. Send curriculum vitae and writing samples to Perspective Editor, New England Journal of Medicine, 10 Shattuck St., Boston, MA 02115. 